\title{
ELISA for Aging Biomarkers Induced by Telomere Dysfunction in Human Plasma
}

\author{
Hong Jiang, ${ }^{1}$ Wenqing Chen, ${ }^{1}$ Lihui Qu, ${ }^{1}$ Ying Chen, ${ }^{1}$ Qiang He, ${ }^{1}$ Huiping Wang, ${ }^{1}$ \\ Jianyong Wu, ${ }^{1}$ Zhangfei Shou, ${ }^{1}$ Zhenyu Ju, ${ }^{2,3}$ and Jianghua Chen ${ }^{1}$ \\ ${ }^{1}$ Kidney Disease Center, The First Affiliated Hospital, College of Medicine, Zhejiang University, Hangzhou 310003, China
${ }^{2}$ Institute of Molecular Medicine, Max-Planck-Research Group on Stem Cell Aging, University of Ulm, 89081 Ulm, Germany
${ }^{3}$ Institute of Laboratory Animal Sciences, Max-Planck-Partner Group on Stem Cell Aging, Chinese Academy of Medical Sciences,
Beijing 100864, China
}

Correspondence should be addressed to Jianghua Chen, chenjianghua@zju.edu.cn

Received 21 May 2010; Revised 30 July 2010; Accepted 28 September 2010

Academic Editor: Manoor Prakash Hande

Copyright (๑) 2010 Hong Jiang et al. This is an open access article distributed under the Creative Commons Attribution License, which permits unrestricted use, distribution, and reproduction in any medium, provided the original work is properly cited.

\begin{abstract}
Background. We identified cathelicidin related antimicrobial protein (CRAMP) secreted from telomere dysfunctional bone marrow cells of late generation telomerase knockout mice $\left(\mathrm{G}_{\mathrm{m}} \mathrm{merc}^{-/-}\right)$, increased in blood and various tissues. It can represented human aging and disease. The main aim of this study is to investigate the sensitive direct enzyme-linked immunosorbent assay (ELISA) method to analyze the human aging and disease in plasma and the detailed methods to quantify the direct ELISA of these aging biomarkers. Methods. Telomere lengths of 50 healthy persons are measured with real-time PCR in blood cells. Plasma samples from all subjects are analyzed using direct ELISA. Results. From 25 years old person to 78 years, the telomere length becomes shorter during aging. In blood plasma, the expression levels of CRAMP increases during human aging. There is the reverse correspondence between the telomere length and the plasma CRAMP level. We also find that the fresh plasma, the frozen plasma which thawed less than 3 times, and the plasma kept in the room temperature less than 3 hours are better for the ELISA analyze of CRAMP in the plasma. Conclusion. This CRAMP ELISA could become a powerful tool for investigating the relationship between human aging and telomere length shortening.
\end{abstract}

\section{Introduction}

Telomeres cap the chromosome ends and prevent the activation of DNA damage checkpoints inducing cell cycle arrest (senescence) or apoptosis [1,2]. Lots of research reported that telomere shortening occurred during human aging and chronic diseases [3]. In addition, mutations in the enzyme telomerase lead to telomere shortening, impaired tissue maintenance, and a shortened lifespan in humans [4-7] and mice [8-11]. These genetic experiments and diseases showed that telomere shortening could impair with organ maintenance and shorten lifespan. However, the actual contribution of dysfunctional telomeres to natural human aging and diseases remains under debate. Accumulation of senescent cells has been detected in skin of aging humans [12] and primates [13] but not in other organs such as muscle [14] or liver [15]. In aging telomerase knockout mice
$\left(\mathrm{G} 4 \mathrm{mTerc}{ }^{-/-}\right)$, telomere dysfunction is associated with a decline in stem cell function, impaired organ maintenance, and a shortened lifespan [8-11]. Yet, G4mTerc ${ }^{-/-}$mice do not show an accumulation of senescent cells [11]. There is emerging evidence that senescent cells can be cleared in vivo by induction of apoptosis [11] and immune responses [16].

We identified CRAMP secreted from telomeredysfunctional bone-marrow cells of late-generation telomerase knockout mice $\left(\mathrm{G}_{4} \mathrm{mTerc}^{-/-}\right)$, increased in blood and in various tissues of aging $\mathrm{G} 4 \mathrm{mTerc}^{-/-}$mice and represented human aging and disease [17]. The results indicate that the telomere length shortened with aging and depend on the other aging markers which connect with each other. Therefore, the impact of telomere dysfunction on aging might be underestimated by experiments trying to detect senescent cells. 
In vitro studies on human cells indicate that low levels of telomere dysfunction precede cellular senescence in culture [18]. The identification of marker proteins indicating low levels of telomere dysfunction in presenescent cells could help to determine the influence of telomere dysfunction and DNA damage on human aging and disease. So the clinicians are gradually interested in the identification of markers, since there is growing population of humans suffering from disease associated with aging.

The main aim of this study is to investigate the sensitive direct enzyme-linked immunosorbent assay (ELISA) method to analyze the human aging and disease in plasma and the detailed methods to quantify the direct ELISA of these aging biomarkers.

\section{Experimental}

2.1. Human Samples. The studies on human samples were conducted after the declaration of Helsinki. All samples were used anonymously. All normal human samples have given written consent to provide blood samples.

2.2. Telomere Length Measurement ( $q$ PCR Protocol). We used a quantitative PCR method to determine telomere length in whole tissue lysates derived from liver biopsies. First, we confirmed telomere length measurement by qPCR correlated with the results obtained by Southern blotting-a gold standard in measuring telomere length. Taq SYBR Green supermix with ROX (Bio-RAD) was used as master mix. The total reaction volume was $25^{-1}$ containing $25 \mathrm{ng}$ of genomic DNA Measurements were performed on the ABI 7300 RealTime PCR system (Applied Biosystems, Foster City, CA). As a standard, a reference DNA sample (BJ26.5 cells) was included for each measurement to control the day-to-day variations. Individual DNA samples were measured in triplicates.

The composition of $\mathrm{T}$ and $\mathrm{S}$ PCR reaction mixes were identical except for the oligonucleotide primers. The final telomere primer concentrations were as follows: for telomere amplification (T): tel1, $100 \mathrm{nM}$; tel2, $900 \mathrm{nM}$. For amplification of the single-copy gene (S) (human $\beta$-globin): hbg1, $300 \mathrm{nM}$; hbg2, $700 \mathrm{nM}$. The primer sequences (written 5 ' to $3 \prime$ ) were

\section{tel 1b, CGGTTTGTTTGGGTTTGGGTTTGGGTT- TGGGTTTGGGTT \\ tel 2b, GGCTTGCCTTACCCTTACCCTTACCCT- TACCCTTACCCT \\ hbg1, GCTTCTGACACAACTGTGTTCACTAGC hbg2, CACCAACTTCATCCACGTTCACC}

The thermal cycling profile for both amplicons began with $95 \circ \mathrm{C}$ incubation for 10 minutes. For telomere PCR, there followed 30 cycles of $95 \circ \mathrm{C}$ for 15 seconds, $56 \circ \mathrm{C}$ for 1 minute. For hbg PCR, there followed 35 cycles of $95 \circ \mathrm{C}$ for 15 seconds, $54 \circ \mathrm{C}$ for 1 minute.

The relative T/S ratios were converted to telomere length in base pairs using the correlation curve of the relative T/S ratio determined by $\mathrm{qPCR}$ with $\mathrm{TRF}$ length determined

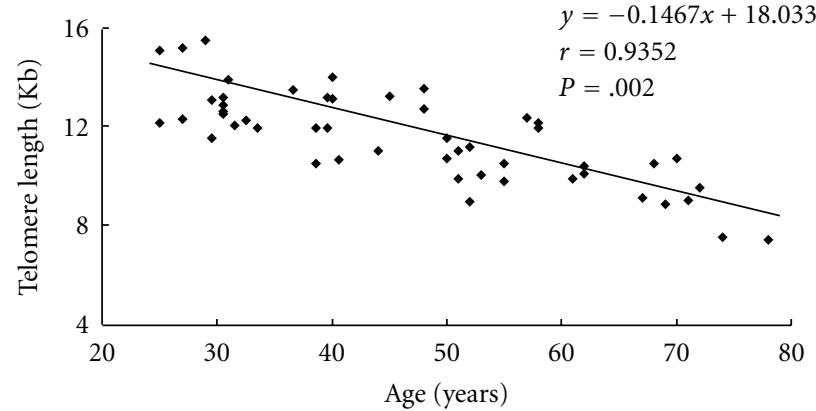

FIGURE 1: Telomere length of healthy people. Telomere lengths of these healthy persons are measured with real-time PCR in blood cells. From 25-year old person to 78 years, the telomere length becomes shorter during aging.

by Southern blot analysis of the above-described set of 11 standard cell lines.

2.3. Direct Enzyme-Linked Immunosorbent Assay (ELISA). Microwell plates (NUNC) were coated with $100^{-} \mathrm{L}$ of plasma (2-time dilution) and standard proteins: CRAMP $100 \mathrm{ng}$, $50 \mathrm{ng}, 25 \mathrm{ng}, 12.5 \mathrm{ng}, 6.25 \mathrm{ng}, 3.125 \mathrm{ng}, 1.6 \mathrm{ng}$, and $0 \mathrm{ng}$ at $4 \circ \mathrm{C}$ overnight. The coated plates were washed three times with PBS-Tween wash solution and then incubated with the first antibody (CRAMP (Cell Signaling) 1:100) either overnight at $4 \circ \mathrm{C}$ or for $2 \mathrm{~h}$ at room temperature (RT). After washing the plates three times with PBS-Tween, the assay was performed by using $100^{-1}$ of HRP-hapten conjugate secondary antibody incubated at RT for $1 \mathrm{~h}$. After five washes with PBS-Tween, $100^{-1}$ of tetramethyl benzidine peroxidebased substrate solution was added to each well, and $30 \mathrm{~min}$ later, $50^{-1}$ of $2 \mathrm{M} \mathrm{H}_{2} \mathrm{SO}_{4}$ was added to each well to stop the reaction. The absorbances were read in the microplate reader in dual-wavelength mode (450-540 nm).

2.4. Statistical Analysis. SPSS 16.0 and GraphPad Prism were used for statistical analyses. The one-sample KolmogorovSmirnov test was used to test for normal distribution of the data. Data are expressed as the mean \pm SD or median (interquartile range) as appropriate. The unpaired Student's $t$-test was used to generate $P$ values for all of the datasets. The error bars represent SD in all figures.

\section{Result}

3.1. Telomere Length of Healthy People. Healthy samples come from 50 healthy persons ( 25 females and 25 males), and their median age is 46.5 , standard deviation is 15.5 . Telomere lengths of these healthy persons are measured with real-time PCR in blood cells. From 25 years old person to 78 years, the telomere length becomes shorter during aging (Figure 1).

3.2. Evaluation of CRAMP in Healthy People. Plasma samples from all subjects are analyzed using direct ELISA, and the data are normalized using internal standards. In blood 


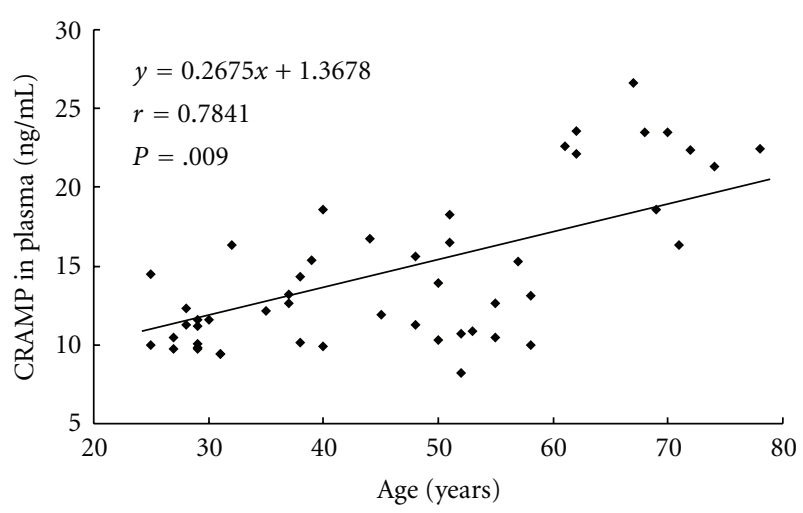

FIGURE 2: Evaluation of CRAMP in healthy people. In blood plasma, the expression levels of CRAMP increases during human aging.

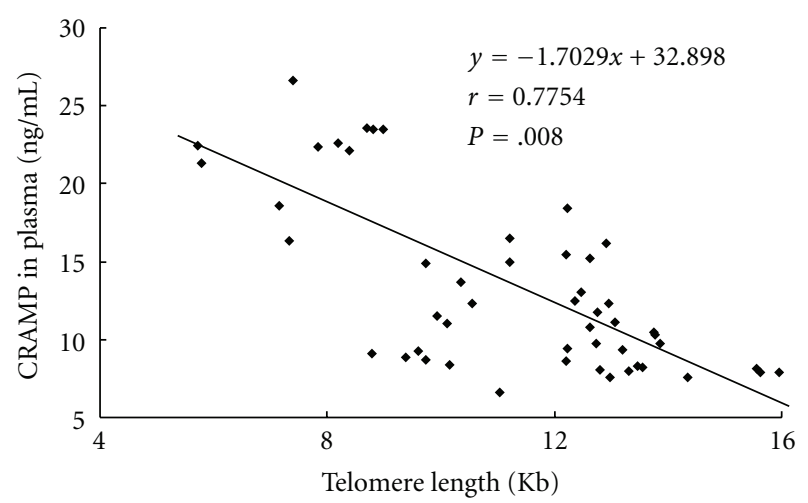

FIgURE 3: The relationship between telomere length and CRAMP level. There is the reverse correspondence between the telomere length and the plasma CRAMP level.

plasma, the expression levels of CRAMP increases during human aging (Figure 2).

3.3. The Relationship between Telomere Length and CRAMP Level. We identified CRAMP secreted from telomeredysfunctional bone-marrow cells of late-generation telomerase knockout mice (G4mTerc $\left.{ }^{-/}\right)$, increased in blood and in various tissues of aging $\mathrm{G} 4 \mathrm{mTerc}^{-/-}$mice and represented human aging and disease (PNAS). In this study we also find the reverse correspondence between the telomere length and the plasma CRAMP level (Figure 3).

3.4. Standardization of ELISA for CRAMP. We get the plasma from 10 healthy persons, each one sacrificed blood at 6 times. That lead us set up the study for the plasma ELISA analyzing at fresh plasma, stand in the room temperature for 1 hour, 2 hours, 3 hours, 4 hours, 5 hours, and we also freeze down the plasma at $-80 \circ \mathrm{C}$, then we thaw the samples for 1 time, 2 times, 3 times, 4 times, 5 times, and we also have one sample keep in $4 \circ \mathrm{C}$ overnight.

In all these samples we test the specificity and sensitivity of CRAMP ELISA. The results show that the fresh plasma has the highest ELISA data, and the plasma keep in $4 \circ \mathrm{C}$ overnight or in the room temperature less than 3 hours, thawed less than 3 times have little lower data, but the statistics does not show the significant difference. But the plasma keep in the room temperature more than 4 hours, thawed more than 4 times have the higher data; the statistics shows the significant difference (Figure 4(a)).

The results also show that the fresh plasma has the highest ELISA data, and the plasma has been kept in $4 \circ \mathrm{C}$ over 1 night, 2, 3, 4, 5 nights or in the room temperature for 1 day, $2,3,4,5$ days have much lower data, and the statistics show the significant difference (Figure 4(b)).

\section{Discussion}

Aging is one of the major risk factors for human health and disease. Accumulating evidences suggested that telomere length in tissue cells is a marker for biological aging $[1,2]$. In this study, telomere lengths of these healthy persons are measured with-real time PCR in blood cells. From 25year old person to 78-year old fifty healthy individuals, the telomere length becomes shorter during aging, as the usual reports [7-9]. And the aging rate we could calculate in this study is $19 \mathrm{Bp}$ telomere shorts each year, also as the usual reports [10-12]. That is why the telomere length is considered as the aging marker.

We identified CRAMP secreted from telomere-dysfunctional bone-marrow cells of late-generation telomerase knockout mice $\left(\mathrm{G} 4 \mathrm{mTerc}^{-/-}\right)$, increased in blood and in various tissues of aging G4mTerc ${ }^{-/-}$mice and represented human aging and disease [17]. In this study, we get 50 healthy persons whose ages are from 25 to 78 years old, to analyze the CRAMP levels in human plasma. We find that the young persons have lower CRAMP levels and the old persons have significant higher CRAMP secretion in plasma. We also could find the CRAMP secreting higher with the human aging, and the SPSS statistics show the significant results. CRAMP secretes higher when the telomere length shortens. This means that CRAMP level could show the human aging, and there must be some detail correlation between telomere shortening and CRAMP secreting, and they both contribute to the human aging. That needs a lot of detailed studies.

When we analyze the CRAMP ELISA, we always get plasma samples from clinical department. These samples may be stored for long time, may be used many times. And we want to know the exact CRAMP level from these samples, make the results special and sensitive. Except the ELISA protocol, there must be some other factors that influence the results. The different time point samples ELISA results show that the fresh plasma has the highest ELISA data, and the plasma keep in $4 \circ \mathrm{C}$ overnight or in the room temperature less than 3 hours, thawed less than 3 times have little lower data, but the statistics does not show the significant difference. But the plasma keep in the room temperature more than 4 hours, thawed more than 4 times have the higher data, the statistics shows the significant difference. And the plasma keep in 4०C over 1 night, 2, 3, 4, 5 nights or in the room temperature for 1 day, $2,3,4,5$ days have much lower data, and the statistics show the significant difference. This means that when we analyze the CRAMP levels, we must make sure that the plasma samples are fresh, 


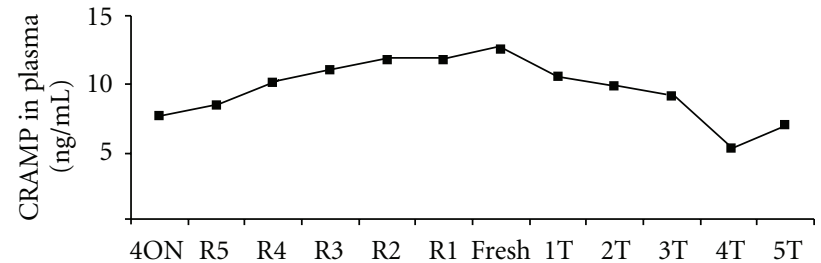

(a)

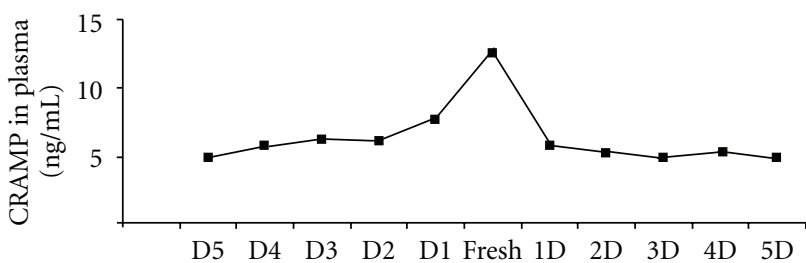

(b)

FIgURE 4: Standardization of ELISA for CRAMP. (a) The results show that the fresh plasma has the highest ELISA data, and the plasma kept in $4 \circ \mathrm{C}$ overnight or in the room temperature less than 3 hours, and the plasma thawed less than 3 times have little lower data, but the statistics does not show the significant difference. But the plasma kept in the room temperature more than 4 hours, thawed more than 4 times have the higher data, the statistics shows the significant difference. (b) The results show that the fresh plasma has the highest ELISA data, and the plasma kept in $4 \circ \mathrm{C}$ over 1 night, 2, 3, 4, 5 nights or in the room temperature for 1 day 2, 3, 4, 5 days have much lower data, and the statistics show the significant difference.

at least the stored samples should be thawed less than 3 times. Otherwise you will get the wrong data.

In conclusion, this CRAMP ELISA could become a powerful tool for investigating the relationship between human aging and telomere length shortening. The detail mechanisms need much more researches. We still need to prove the ELISA sensitivity and specificity through the way of samples' high quality control.

\section{Acknowledgments}

This study was supported by grants from the National Nature Science Foundation of China (30900689), the special Foundation of Young Scientists in Zhejiang Province (2009QN004), the Foundation for University PHD (20090101120095), and the special Foundation of Qianjiang Rencai in Zhejiang Province (2010R10083). H. Jiang and W. Chen worked equally for this paper.

\section{References}

[1] W. E. Wright and J. W. Shay, "The two-stage mechanism controlling cellular senescence and immortalization," Experimental Gerontology, vol. 27, no. 4, pp. 383-389, 1992.

[2] H.-W. Lee, M. A. Blasco, G. J. Gottlieb, J. W. Horner II, C. W. Greider, and R. A. DePinho, "Essential role of mouse telomerase in highly proliferative organs," Nature, vol. 392, no. 6676, pp. 569-574, 1998.

[3] H. Jiang, Z. Ju, and K. L. Rudolph, "Telomere shortening and ageing," Zeitschrift fur Gerontologie und Geriatrie, vol. 40, no. 5, pp. 314-324, 2007.

[4] T. Vulliamy, A. Marrone, I. Dokal, and P. J. Mason, "Association between aplastic anaemia and mutations in telomerase RNA," Lancet, vol. 359, no. 9324, pp. 2168-2170, 2002.

[5] J. R. Mitchell, E. Wood, and K. Collins, "A telomerase component is defective in the human disease dyskeratosis congenita," Nature, vol. 402, no. 6761, pp. 551-555, 1999.

[6] K. D. Tsakiri, J. T. Cronkhite, P. J. Kuan et al., "Adultonset pulmonary fibrosis caused by mutations in telomerase," Proceedings of the National Academy of Sciences of the United States of America, vol. 104, no. 18, pp. 7552-7557, 2007.

[7] M. Y. Armanios, J. J.-L. Chen, J. D. Cogan et al., "Telomerase mutations in families with idiopathic pulmonary fibrosis," New England Journal of Medicine, vol. 356, no. 13, pp. 13171326, 2007.
[8] K. L. Rudolph, S. Chang, H.-W. Lee et al., "Longevity, stress response, and cancer in aging telomerase-deficient mice," Cell, vol. 96, no. 5, pp. 701-712, 1999.

[9] E. Herrera, E. Samper, J. Martín-Caballero, J. M. Flores, H.-W. Lee, and M. A. Blasco, "Disease states associated with telomerase deficiency appear earlier in mice with short telomeres," EMBO Journal, vol. 18, no. 11, pp. 2950-2960, 1999.

[10] L.-Y. Hao, M. Armanios, M. A. Strong et al., "Short telomeres, even in the presence of telomerase, limit tissue renewal capacity," Cell, vol. 123, no. 6, pp. 1121-1131, 2005.

[11] A. R. Choudhury, Z. Ju, M. W. Djojosubroto et al., "Cdknla deletion improves stem cell function and lifespan of mice with dysfunctional telomeres without accelerating cancer formation," Nature Genetics, vol. 39, no. 1, pp. 99-105, 2007.

[12] G. P. Dimri, X. Lee, G. Basile et al., "A biomarker that identifies senescent human cells in culture and in aging skin in vivo," Proceedings of the National Academy of Sciences of the United States of America, vol. 92, no. 20, pp. 9363-9367, 1995.

[13] U. Herbig, M. Ferreira, L. Condel, D. Carey, and J. M. Sedivy, "Cellular senescence in aging primates," Science, vol. 311, no. 5765, article 1257, 2006.

[14] J. C. Jeyapalan, M. Ferreira, J. M. Sedivy, and U. Herbig, "Accumulation of senescent cells in mitotic tissue of aging primates," Mechanisms of Ageing and Development, vol. 128, no. 1, pp. 36-44, 2007.

[15] S. U. Wiemann, A. Satyanarayana, M. Tsahuridu et al., "Hepatocyte telomere shortening and senescence are general markers of human liver cirrhosis," FASEB Journal, vol. 16, no. 9, pp. 935-942, 2002.

[16] W. Xue, L. Zender, C. Miething et al., "Senescence and tumour clearance is triggered by p53 restoration in murine liver carcinomas," Nature, vol. 445, no. 7128, pp. 656-660, 2007.

[17] H. Jiang, E. Schiffer, Z. Song et al., "Proteins induced by telomere dysfunction and DNA damage represent biomarkers of human aging and disease," Proceedings of the National Academy of Sciences of the United States of America, vol. 105, no. 32, pp. 11299-11304, 2008.

[18] Y. Zou, A. Sfeir, S. M. Gryaznov, J. W. Shay, and W. E. Wright, "Does a sentinel or a subset of short telomeres determine replicative senescence?" Molecular Biology of the Cell, vol. 15, no. 8, pp. 3709-3718, 2004. 


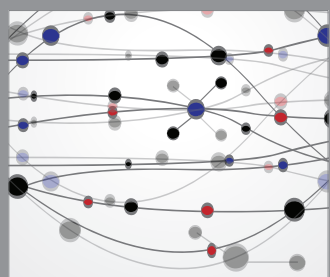

The Scientific World Journal
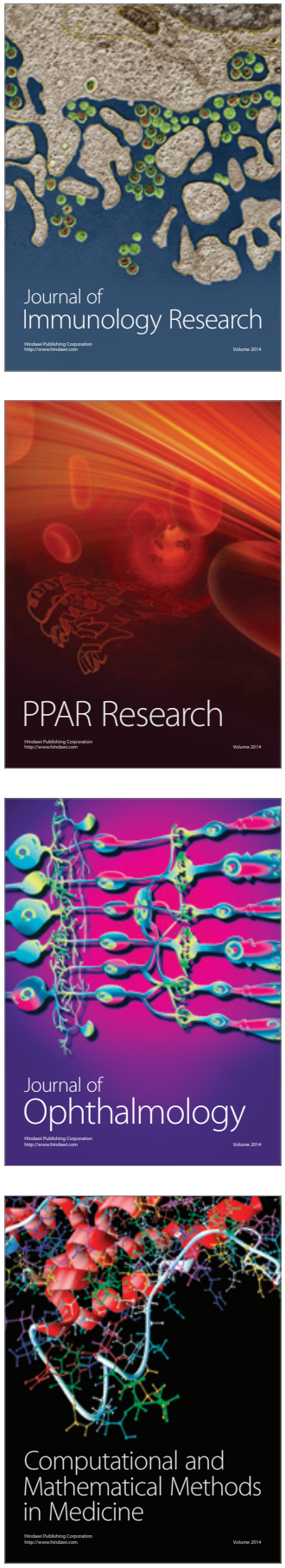

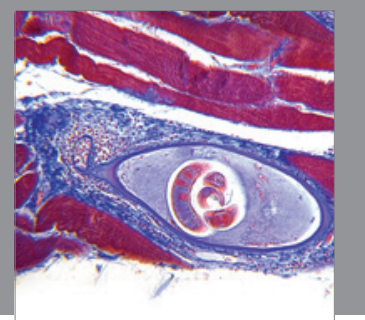

Gastroenterology

Research and Practice
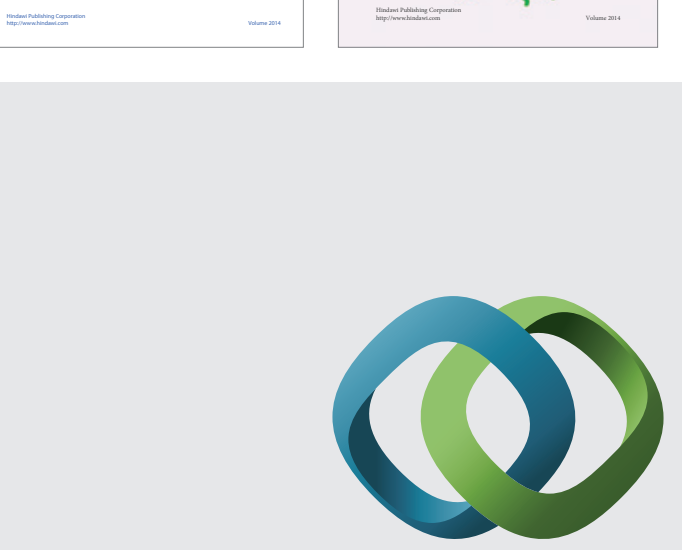

\section{Hindawi}

Submit your manuscripts at

http://www.hindawi.com
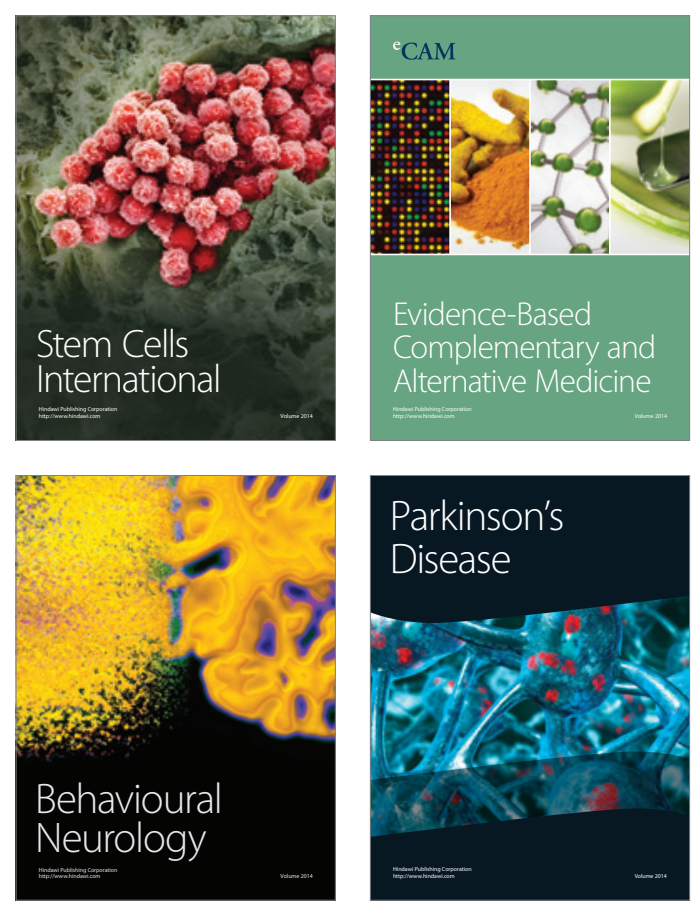

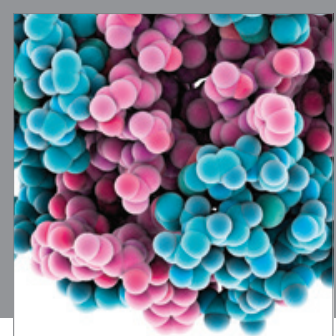

Journal of
Diabetes Research

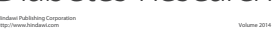

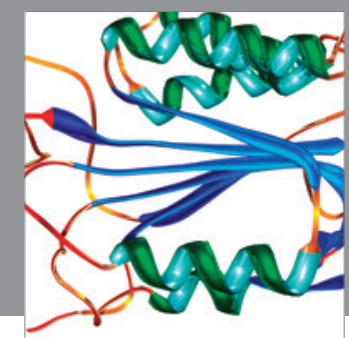

Disease Markers
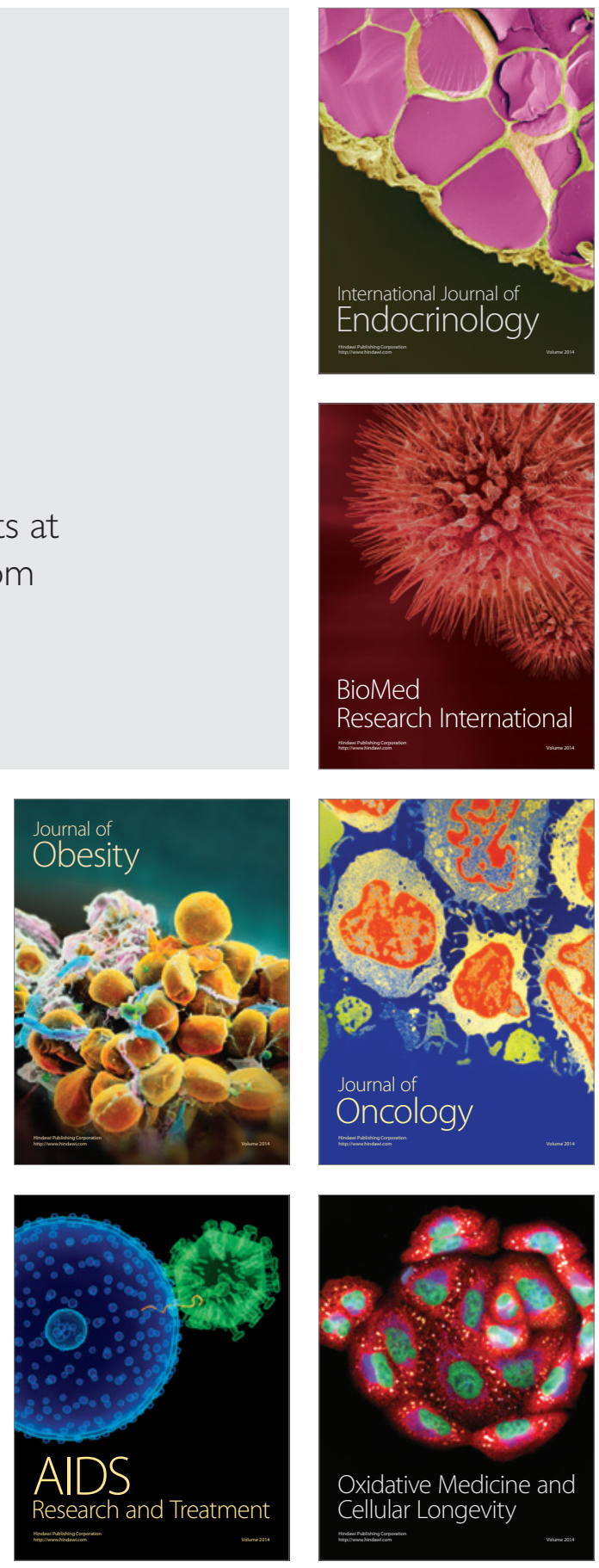